\title{
Salvage treatment for lymph node recurrence after radical resection of esophageal squamous cell carcinoma
}

Jie Chen, Wenming Yin, Hui Yao and Wendong Gu* (D)

\begin{abstract}
Background: Patients with regional lymph node recurrence after radical resection of esophageal cancer have poor therapeutic outcomes. Currently, there is no standard treatment for regional lymph node recurrence, and its prognostic risk factors are not well-understood. This study retrospectively analyzed 83 patients with postoperative regional lymph node recurrence after radical resection of esophageal squamous cell carcinoma. The aim was to evaluate the clinical efficacy and prognostic factors of salvage radiotherapy with or without chemotherapy in these patients.
\end{abstract}

Methods: The survival and prognostic factors of 83 patients with esophageal squamous cell carcinoma with regional lymph node recurrence after radical surgery were retrospectively analyzed. All patients underwent radiotherapy, of which 74 patients received volumetric modulated arc therapy (VMAT), 9 patients received three-dimensional conformal radiation therapy (3DCRT), administered using a conventional segmentation protocol with a dose distribution range of 50.4-66.2Gy (median dose of 60Gy). In total, 41 patients received radiotherapy alone, 42 received radiotherapy combined with chemotherapy, and the concurrent chemotherapy regimen was mainly composed of either platinum or fluorouracil monotherapy, except for 4 patients who were given 5 -fluorouracil plus platinum (FP) or paclitaxel plus platinum (TP).

Results: The median follow-up time was 24 (range, 9-75) months. The overall survival (OS) rates at 1 year, 2 years, 3 years, and 5 years were 83.0, 57.1, 40.1, and 35.1\%, respectively. The median overall survival (OS) time was 18 (range, 575) months. The 3 -year survival rate was $47.5 \%$ in patients with radiation alone and $41.9 \%$ in patients receiving concurrent chemoradiotherapy $(p=0.570)$, while the response rate $(C R+P R)$ in those two groups was 73.2 and $91.4 \%$, respectively. By multivariate analysis of $O S$, age (worse in younger patients, $p=0.034$ ) was found to be significantly associated with disease prognosis. The commonly toxicities were esophagitis, neutropenia and anemia. 18\% patients experienced grade 3 toxicity and no treatment-related death occurred.

Conclusions: These results of this retrospective analysis suggest that radiotherapy with or without chemotherapy is an effective and feasible salvage treatment for lymph node recurrence after radical resection of esophageal squamous cell carcinoma.

Keywords: Esophageal squamous cell carcinoma, Radical surgery, Lymph node recurrence, Radiotherapy, Chemoradiotherapy

\footnotetext{
* Correspondence: guwendong1415@czfph.com

Department of Radiation Oncology, The Third Affiliated Hospital of Soochow

University, No. 185 Juqian Street, Changzhou 213003, China
}

(c) The Author(s). 2019 Open Access This article is distributed under the terms of the Creative Commons Attribution 4.0 International License (http://creativecommons.org/licenses/by/4.0/), which permits unrestricted use, distribution, and reproduction in any medium, provided you give appropriate credit to the original author(s) and the source, provide a link to the Creative Commons license, and indicate if changes were made. The Creative Commons Public Domain Dedication waiver (http://creativecommons.org/publicdomain/zero/1.0/) applies to the data made available in this article, unless otherwise stated. 


\section{Introduction}

In China, surgical resection is the preferred treatment for resectable esophageal cancer. However, the 5-year overall survival rates of these patients are low, ranging from 31 to $55 \%[1,2]$. In addition, $43 \% \sim 53 \%$ of patients who undergo surgery experience local recurrence and/or distant metastasis, and the median time to recurrence ranges from 10 to 12 months. The most common local recurrence sites are anastomotic, supraclavicular lymph nodes and mediastinal lymph nodes $[1,3,4]$. Treatments for local recurrence include chemoradiotherapy, radiotherapy, surgery, chemotherapy and stringent supportive care. A retrospective study by Kosuga et al. [5]indicated that lymphadenectomy, radiotherapy, and chemoradiotherapy were effective salvage treatments. Lymphadenectomy has been reported to be feasible for postoperative cervical lymph node recurrence [6-8]. Radiotherapy administered locally was also found to be a promising option to control lymph node recurrence after curative resection [9-11]. Given that chemoradiotherapy is effective in mounting local control and reducing distant recurrence by promoting radiosensitivity, while eliminating micrometastases, several studies have verified the effectiveness of concurrent chemoradiotherapy [12-14]. However, the prevailing data on this treatment is not conclusive and many therapeutic strategies for postoperative lymph node recurrence after esophageal cancer are controversial. Herein, we determined the prognostic factors of patients with esophageal squamous cell carcinoma with regional lymph node recurrence after radical surgery and the efficacy of radiotherapy with or without chemotherapy for lymph node recurrence in such patients.

\section{Materials and methods}

\section{Study population}

We retrospectively analyzed the survival and prognosis factors of patients who underwent radiation therapy for postoperative regional lymph node recurrence after resection of esophageal cancer in the Third Affiliated Hospital of Suzhou University from January 2012 to January 2018. Data was obtained from medical records, radiotherapy plans and video material. A total of 83 patients with lymph node recurrence following curative resection of esophageal squamous cell carcinoma were enrolled in the study, and all patients provided informed consent. The inclusion criteria included: (1) pathology confirmed as esophageal squamous cell carcinoma; (2) initial treatment was radical surgery without neoadjuvant therapy or postoperative prophylactic radiotherapy; (3) lymph node recurrence was diagnosed by 2 senior physicians experienced in imaging or pathological data evaluation, including the supraclavicular, mediastinal and left gastric lymphatic drainage area; (4) Kanofsky Performance Status (KPS) $\geq 70$; (5) neither anastomotic recurrence nor distant metastasis was present after CT examination at this hospital before radiotherapy;
(6) diagnosis criteria of lymph node recurrence: 1) CT showed the shortest diameter of the suspicious lymph node $\geq 1 \mathrm{~cm}$, the longest diameter of the lymph nodes beside the esophagus, at the corner between the esophagus and trachea, or at the cardio-diaphragmatic angle $>5 \mathrm{~mm}$, and the longest diameter of abdominal lymph node $\geq 5$ mm [15-17]; or 2) CT showed more than 3 lymph node clustered or lymph nodes fused to each other; or 3) CT showed lymph node center necrosis; or 4) Positron Emission Tomography-Computed Tomography (PET/CT) showed high FDG uptake lesions in the esophageal lymph node drainage area (SUV cut-off value > 2.5 [18-20]); or 5) puncture pathology confirmed the existence of lymph node metastasis.

\section{Treatment}

All patients received intensity-modulated radiation therapy (VMAT and 3DCRT radiotherapy). Patients were placed in supine position, a cradle for immobilization was made with vacuum (Gray) followed by body membrane fixation (Klarity) and spiral CT positioning (Siemens Somatom Sensation Open). Each patient was scanned from the axis (C2) to the second lumbar vertebrae (L2) level to cover the entire neck, lung, esophagus and abdominal lymph node regions. Images were reconstructed to $5 \mathrm{~mm}$ thick after CT enhancement scanning and transferred to the Treatment Planning System (TPS) to determine the target area and radiation therapy plan, and to optimize the measurement. Target area delineation: The gross tumor volume (GTV) was defined as recurrent lymph nodes identified by CT scans or PET/CT. The clinical target volume (CTV) was defined as GTV plus a margin of $10 \mathrm{~mm}$ around GTV and manually modified to meet the following criteria: 1) include the nearest adjacent lymphatic drainage regions of the metastasis lymph node; 2) avoid normal organs such as the pleura, vertebral bodies, and blood vessels. The planning tumor volume (PTV) was defined as the CTV plus the placement of $5 \mathrm{~mm}$ around the CTV. Both the 3D-CRT and VMAT treatment plans were designed by the Monaco Radiotherapy Treatment Planning System (Elekta). Radiation therapy (RT) was administered with a linear 6-MV photon accelerator (Elekta Axesse). The daily fractional dose of RT was 1.82.0Gy, administered 5 days per week, and the total dose was 50.4-66.2Gy. The dose of OAR was administered as follows: maximum dose of spinal cord $<45 \mathrm{~Gy}$, mean heart dose $<35 \mathrm{~Gy}$, lung doseV $20<30 \%$. Response evaluation was assessed 1 month after radiation treatment. Patients were followed up at intervals of 3 to 6 months after treatment. The response assessment included medical history, ultrasonography, chest and abdomen CT and PET/CT. Response Evaluation Criteria in Solid Tumors (RECIST 1.1) were used to determine tumor response, and infield disease progression was defined as treatment failure. 


\section{Statistical analyses}

Overall survival (OS) time was calculated as the time interval from the initiation of radiotherapy to death or termination of follow-up after relapse. The OS rate was estimated by Kaplan-Meier method and the differences in survival rates after univariate analysis were assessed with the log-rank test. Factors with $\mathrm{p}<0.2$ were included in multivariate analysis. Cox's proportional hazards regression model was used for multivariate survival analysis. All statistical analyses were performed using SPSS 21.0 software. $P$ values $<0.05$ were regarded as statistically significant. Short-term efficacy was assessed based on the solid tumor efficacy evaluation criteria (RECIST 1.1). The tumor response was defined as a complete response (CR) and a partial response (PR). Toxicity was assessed and documented according to National Cancer Institute Common Terminology Criteria for Adverse Events (CTCAE 4.1).

\section{Results}

\section{Patients and tumor characteristics}

A total of 83 patients were eligible for this study, and their clinical characteristics are listed in Table 1. All patients completed radiotherapy, 41 patients received radiotherapy alone, 42 patients received radiotherapy combined with chemotherapy and 35 of the 42 patients received concurrent chemoradiotherapy. The median radiation dose was $60 \mathrm{~Gy}$ (range, 50.4 to $66.2 \mathrm{~Gy}$ ). A total of 46 patients received radiation above the 60Gy dose and 37 received radiation of less than 60Gy. Seventy-four patients used VMAT technology and nine patients used 3D-CRT technology. All patients received regular follow-up after treatment. The median follow-up time was 24 months (range, 9-75 months). The median time from surgery to diagnosis of regional lymph node recurrence was 5 months (range, 1-59 months). The recurrent lymph nodes were mainly distributed in the mediastinum and supraclavicular regions. Six cases had supraclavicular lymph node recurrence, 50 cases had mediastinal lymph node recurrence, 2 cases had abdominal lymph node recurrence and the remaining 25 cases had multiregional lymph node metastasis of which 23 cases experienced supraclavicular and mediastinal lymph node recurrence. The median volume of the recurrent tumor was $5.5 \mathrm{~cm}^{3}$ (range, $1.22-123.21 \mathrm{~cm}^{3}$ ). According to previous works investigating the prognostic factors, age, postoperative stage of esophageal cancer, interval to recurrence, lymph node recurrence sites, number of recurrent nodes, recurrent lymph node size, with or without concurrent chemotherapy, radiation dose, chemotherapy regimen and tumor response rate were included in the univariate analysis to evaluate their impact on prognosis. The cutoff values of the factors including age, recurrent lymph node size and radiation dose were decided according to the median.

\section{Treatment outcome}

The overall tumor response rate was $81.9 \%$, with 10 patients showing complete response (CR) and 58 patients showing partial response (PR) (Table 2). The 1-year, 2year, and 3-year, 5-year OS rates were 83.0, 57.1, 40.1, and $35.1 \%$, respectively. The median OS was 18 months (range, 5-75 months). In the radiotherapy group alone, the 3-year survival rate, the response rate and the median OS were $47.5,73.2 \%$ and 22 months, respectively, while the 3-year survival rate, the response rate and the median OS were $41.9,91.4 \%$ and 16 months, respectively, in patients who received concurrent chemoradiotherapy (Fig. 1).

\section{Toxicity}

The main toxicities were esophagitis, neutropenia and anemia, and most of the toxicity were of grade 1 or 2 . Grade 3 toxicities were observed in 15 patients, including: skin damage (1.2\%), nausea and vomiting (1.2\%), bronchitis $(1.2 \%)$, neutropenia $(4.8 \%)$, radiation pneumonitis $(9.6 \%)$. Patients with high dose ( $\geq 60 \mathrm{~Gy})$ or radiotherapy combined with chemotherapy were more likely to have grade 3 toxicity. No grade 4 or 5 toxicity was observed in any patients, and no treatment-related death occurred.

\section{Statistical analysis}

In the univariate analysis of OS, no statistically significant factors were found to be associated with disease prognosis. In the multivariate analysis of OS, age (worse in younger patients, $P=0.034$ ) was characterized as a significant independent prognostic factor. (Table 3).

\section{Discussion}

Our results showed that radiotherapy, with or without chemotherapy, is an effective and feasible salvage treatment for lymph node recurrence after radical resection of ESCC. The 1-year, 3-year, and 5-year OS rates were 83.0, 40.1, and $35.1 \%$, with the median OS of 18 months. In the radiotherapy group, the 3 -year survival rate was $47.5 \%$, the response rate was $73.2 \%$ and the median OS was 22 months. In patients who received concurrent chemoradiotherapy, the 3-year survival rate, the response rate and the median OS were $41.9,91.4 \%$ and 16 months, respectively. Grade 3 toxicity was low (18\%) and there were no treatment-related deaths that occurred. In the multivariate analysis of OS, age was characterized as a significant independent prognostic factor $(P=0.034)$. Similar to previous studies, our results are robust. In the study of $\mathrm{Ma}$ et al. [10], 98 patients were randomly enrolled to undergo either three-dimensional conformal radiotherapy alone (group A) or concurrent chemoradiotherapy (group B). All 
Table 1 Clinical characteristics of patients $(n=83)$

\begin{tabular}{|c|c|c|c|}
\hline Characteristic & Group & No. & $(\%)$ \\
\hline \multirow[t]{3}{*}{ Age (year) } & Median (range) & $63(45-76)$ & \\
\hline & $\geq 63$ & 43 & (52) \\
\hline & $<63$ & 40 & (48) \\
\hline \multirow[t]{2}{*}{ Gender } & Male & 67 & (81) \\
\hline & Female & 16 & (19) \\
\hline \multirow[t]{2}{*}{ Performance Status (KPS) } & $\geq 80$ & 78 & $(9$ \\
\hline & $70-80$ & 5 & (6) \\
\hline \multirow[t]{3}{*}{ Primary tumor location } & Cervix+Upper thorax & 6 & (7) \\
\hline & Middle thorax & 36 & (43) \\
\hline & Lower thorax & 41 & (49) \\
\hline \multirow[t]{2}{*}{ Radical surgery } & Ivor-Lewis & 48 & (58) \\
\hline & Sweet & 26 & (31) \\
\hline Stage of primary tumor & $\mid+\|$ & 49 & (59) \\
\hline (AJCC 7th edition) & III & 34 & (41) \\
\hline \multirow[t]{3}{*}{ Interval to recurrence (month) } & Median (range) & $5(1-59)$ & \\
\hline & $>6$ & 20 & (24) \\
\hline & $\leq 6$ & 63 & (76) \\
\hline \multirow[t]{4}{*}{ Lymph node recurrence site } & Supraclavicular region & 6 & (7) \\
\hline & Mediastinal & 50 & (60) \\
\hline & Abdominal & 2 & (2) \\
\hline & Multiple & 25 & (30) \\
\hline \multirow[t]{3}{*}{ Recurrent lymph node size $\left(\mathrm{cm}^{3}\right)$} & Median (range) & $5.5(1.22-123.21)$ & \\
\hline & $>5.5$ & 41 & (49) \\
\hline & $\leq 5.5$ & 42 & (51) \\
\hline \multirow[t]{3}{*}{ Number of lymph node recurrence (no.) } & Median (range) & $2(1-6)$ & \\
\hline & Multiple & 64 & (77) \\
\hline & Single & 19 & (23) \\
\hline \multirow[t]{3}{*}{ Radiation dose } & Median (range) & $60(50.4-66.2)$ & \\
\hline & $\geq 60 G y$ & 46 & (55) \\
\hline & $<60 G y$ & 37 & (45) \\
\hline \multirow[t]{2}{*}{ Treatments after recurrence } & $\mathrm{RT}^{\mathrm{a}}$ & 41 & (49) \\
\hline & $\mathrm{RT}+\mathrm{CT}^{\mathrm{b}}$ & 42 & (51) \\
\hline
\end{tabular}

aradiotherapy alone

${ }^{b}$ radiotherapy combined with chemotherapy

patients received a radiation dose of 62-70Gy and the patients in group B received a weekly low dose of cisplatin $\left(30 \mathrm{mg} / \mathrm{m}^{2}\right)$. The median OS and 3-year survival rates of group B (35 months and $46.9 \%$, respectively) were greater than those of group A (19 months and $28.6 \%$, respectively). Our overall 3-year OS rates (47.5\%) were greater than those $(28.6 \%)$ reported by Ma et al. [10] in the RT group, while they were similar in the CCRT group. In addition, researchers found that neither of the treatment modalities brought about any improvements to the 5-year survival rates. VMAT was commonly used in our study. Clinical research and methodological studies relating to the treatment of esophageal cancer have shown that IMRT or VMAT are better than 3DCRT with respect to improved target coverage and conformality, in addition to reduced radiation exposure to adjacent organs [25, 26].This may be the reason why our results were favorable. Previous studies suggested that synergistic effects of concurrent chemoradiotherapy can improve survival. Jingu et al. [24] reported the long-term results of CCRT for postoperative lymph node recurrence in their prospective phase II study. A total of 30 patients were treated for post-operative LR with RT (60Gy) combined with concurrent chemotherapy consisting of two cycles of 


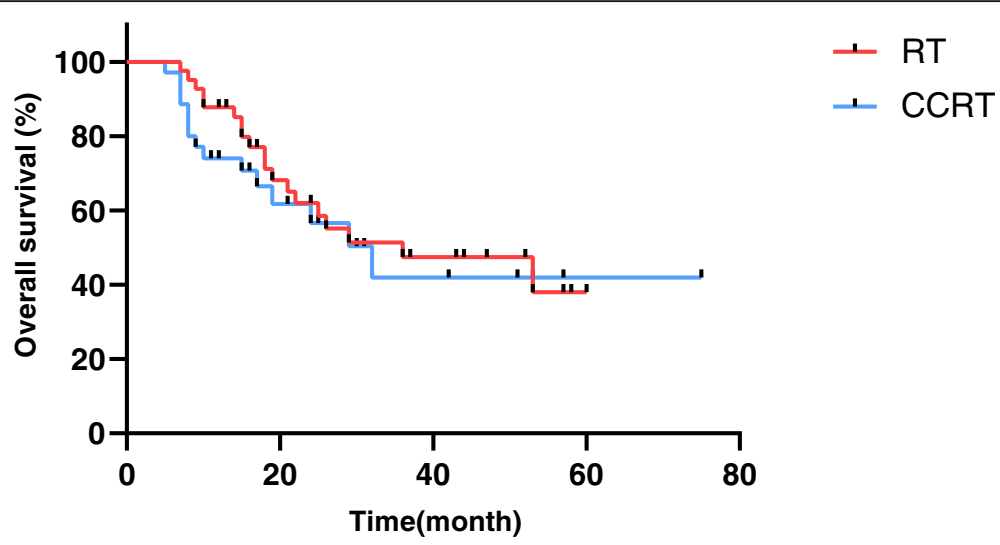

Fig. 1 Overall survival of patients treated with radiotherapy alone and concurrent chemoradiotherapy. The median OS and the 1 years, 3 years OS rates were 22 months, 79.8 , and $47.5 \%$ in the group of patients treated with radiotherapy alone (RT), while that of 16 months, 74.1 and $41.9 \%$ in cases with concurrent chemoradiotherapy (CCRT). In the univariate analysis of OS assessed with the log-rank test, there was no significant differences between the two group $(p=0.570)$

nedaplatin and 5-fluorouracil. The 3-year OS was 38.4\%, with an MST of 21.0 months. Yamashita et al. [22] also reported similar findings in a study that involved 237 patients who received RT or CCRT. The 3-year OS was $39.7 \%$ with CCRT and $20.8 \%$ with RT alone $(\mathrm{p}<0.05)$. In her study, $83 \%$ of patients received CCRT, among which, 5-fluorouracil and cisplatin/ nedaplatin were used in 167 patients. In the present study, Platinum or fluorouracil monotherapy were predominantly used; it may reduce the toxicity compared to reported studies. Despite the controversy in concurrent chemotherapy regimens that are suitable for postoperative lymph node recurrence, the FP regimen produced excellent results for recurrent lymph nodes reported by Zhang et al. [13] Studies on CCRT for patients with locoregional recurrent esophageal carcinomas are limited in countries with the exception of Asia. Baxi el at [27]. treated 14 patients with both adenocarcinoma and SCC. All patients received 58-60Gy, with either cisplatin, fluorouracil, or both. Similar to our results, the median OS was 16 months and the 2-year OS was $21 \%$. Jeene el at [28]. investigated salvage treatment for an isolated lymph node recurrence after curative resection in 22 patients. Treatment consisted of 50.4Gy combined with weekly concurrent paclitaxel and carboplatin therapy. The

Table 2 Tumor response rate

\begin{tabular}{|c|c|c|c|c|c|c|}
\hline \multirow{2}{*}{$\begin{array}{l}\text { Tumor response } \\
\mathrm{CR}^{\mathrm{a}}\end{array}$} & \multicolumn{2}{|c|}{$\begin{array}{l}\text { Total }(n=83) \\
\text { No. }(\%)\end{array}$} & \multicolumn{2}{|c|}{$\begin{array}{l}\text { RT }(n=41) \\
\text { No. }(\%)\end{array}$} & \multicolumn{2}{|c|}{$\begin{array}{l}\text { CCRT }(n=35) \\
\text { №. }(\%)\end{array}$} \\
\hline & 10 & (12.0) & 5 & $(12.2)$ & 5 & (14.3) \\
\hline$P R^{b}$ & 58 & $(69.9)$ & 25 & $(61.0)$ & 27 & (77.1) \\
\hline$S D^{c}$ & 9 & (10.9) & 7 & $(17.1)$ & 2 & (5.7) \\
\hline$P D^{d}$ & 6 & $(7.2)$ & 4 & $(9.7)$ & 1 & (2.9) \\
\hline
\end{tabular}

study reported a median OS was 33 months, which, is better than the findings from the present study. In western countries, it is more common to use neoadjuvant chemoradiotherapy followed by surgery as a standard for the radical treatment of esophageal cancer. However, the dose or the area of re-irradiation may be limited, especially on those infield recurrences. In those studies, adenocarcinomas were mostly the cancers effecting the participants. Although, there was no agreement on prognosis between adenocarcinomas and SCC. In addition, the recurrence at the site of the anastomosis has been reported prognostically unfavorable in those two studies. In this study, the differences in recurrent lymph node size might have been one reason for the difference in the survival periods. The median size of $8.14 \mathrm{~cm}^{3}$ in the CCRT group was significantly greater than that of $4.15 \mathrm{~cm}^{3}$ in the radiotherapy group. Previous studies stated that small recurrent lymph nodes have a better prognosis [10]. There was no other difference between the two groups, including radiation dose (median 60Gy in both groups), interval to recurrence, region of lymph node recurrence, and postoperative staging. Controversies remain regarding the treatment strategy for lymph node recurrence after radical resection in esophageal cancer. Radiotherapy or chemoradiotherapy may be selected as salvage treatment considering the good survival results and low toxicity reported in this study. However, lymph node recurrence, anastomotic recurrence, and distant metastasis occurred even after salvage treatment. Given the presence of micrometastasis, further prospective studies should be carried out to determine populations that have high risk of metastasis so that they may receive intensive therapy.

As for prognostic factors, age was characterized as a significant independent prognostic factor $(P=0.034)$; younger patients had a shorter survival time. Consistent with our findings, both Nemoto el at [9]. and Jingu el at 
Table 3 Univariate and multivariate analysis of the overall survival prognostic factors $(n=83)$

\begin{tabular}{|c|c|c|c|c|}
\hline \multirow[t]{2}{*}{ Variable } & \multicolumn{2}{|c|}{ Univariate analysis } & \multicolumn{2}{|c|}{ multivariate analysis } \\
\hline & No. $x^{2}$ & $P$ & $\overline{H R((95 \% C l)}$ & $P$ \\
\hline
\end{tabular}

\begin{tabular}{llll}
\hline Gender & & & \\
Male & 67 & 1.689 & .194
\end{tabular}

Female

Age

$$
\geq 63 \text { years }
$$$$
<63 \text { year }
$$$$
16
$$

rimary tumor location

Cervix+Upper thorax

Middle thorax 36

Lower thorax 41

Radical surgery

$\begin{array}{ll}\text { Ivor-Lewis surgery } & 48 \\ \text { Sweet surgery } & 26\end{array}$

pT

pT1 +2
pT3 +4

pN

pNO 40

$\mathrm{pN}+$

pStage ${ }^{a}$ (AJCC 7th edition)

$\begin{array}{ll}\text { I+ II } & 49 \\ \text { III } & 34\end{array}$

Interval to recurrence

$\begin{array}{lll}>6 \text { months } & 20 \quad 001 \quad 980\end{array}$

$\leq 6$ months

63

Recurrent lymph node size

$$
\begin{array}{ll}
>5.5 \mathrm{~cm}^{3} & 41 \\
\leq 5.5 \mathrm{~cm}^{3} & 42
\end{array}
$$

Number of recurrent nodes

$\begin{array}{ll}\text { Multiple } & 64 \\ \text { Single } & 19\end{array}$

Region of recurrent nodes

Multiple

Single

$$
58
$$

Lymph node recurrence site

\section{Supraclavicular}

6

Mediastinal

50

Abdominal

Salvage Treatments

$\begin{array}{llll}\text { RT } & 41 & .322 & .570 \\ \text { CCRT }^{\text {b }} & 35 & & \end{array}$

\begin{tabular}{|c|c|c|c|c|c|}
\hline \multirow[t]{2}{*}{ Variable } & \multicolumn{3}{|c|}{ Univariate analysis } & \multicolumn{2}{|c|}{ multivariate analysis } \\
\hline & No. & $x^{2}$ & $P$ & $H R((95 \% C l)$ & $P$ \\
\hline VAMT $^{C}$ & 74 & .248 & .618 & & \\
\hline $3 D C R T^{d}$ & 9 & & & & \\
\hline \multicolumn{6}{|c|}{ Concurrent chemotherapy regimen } \\
\hline platinum & 18 & .801 & .371 & & \\
\hline fluorouracil & 15 & & & & \\
\hline \multicolumn{6}{|l|}{ Radiation dose } \\
\hline$\geq 60 G y$ & 46 & .020 & .888 & & \\
\hline$<60 G y$ & 37 & & & & \\
\hline \multicolumn{6}{|c|}{ Tumor Response } \\
\hline$C R+P R$ & 68 & .331 & .565 & & \\
\hline$S D+P D$ & 15 & & & & \\
\hline
\end{tabular}

Radiation technique
Table 3 Univariate and multivariate analysis of the overall survival prognostic factors $(n=83)$ (Continued)

a postoperative stage of esophageal cancer

${ }^{\mathrm{b}}$ concurrent chemoradiotherapy

cvolumetric modulated arc therapy

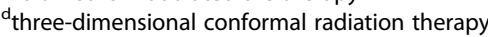

[29].reported that younger patients had a worse prognosis. Biological behavior of tumors in younger patients may be aggressive. Thence, cancer screening is recommended to be early performed. In the present study, there were no other factors observed to be significantly associated with prognosis. Although some common prognostic factors including single lymph node recurrence, single regional lymph node recurrence, and small lymph node have been reported to be associated with better prognosis [10, 12, 14, 30].

The survival rate was not significantly different for a radiation dose that was higher or less than 60Gy ( $p=$ 0.888 ), although patients who received a higher dose had a longer survival time (median OS of 21 months) than those who received a lower dose (median OS of 16 months). In our case, all patients accepted intensity modulated radiotherapy, which could possibly be the reason for our encouraging finding. Raoul et al. [31] reported a median survival time of 10.7 months in patients combined chemotherapy with cisplatin and 5-FU with an RT dose of 60Gy. The low survival rate was associated with factors such as 2DCRT radiotherapy and multiple region recurrences. Kawamoto et al. [12] reported a favorable result with the median OS of 22 months after using a radiation dose of 60-66Gy. Given the advancements in radiotherapy technology, Zhang et al. [23] showed that doses higher than 60Gy significantly improved the progression-free survival and overall survival (median OS of 16.3 months, $p=0.041$ ). However, due to the small size of their sample, and the lack of multivariate analysis, their findings may have been affected by bias. In the study run by $\mathrm{Ma}$ et al. [10], 98 patients received a radiation dose of 62-70Gy. They reported 
exciting finding of a median OS of 35 months in the concurrent chemotherapy group and that of 19 months in the radiotherapy group. Despite the numerous reported dose-related studies so far, the optimal dose for local recurrence after esophageal cancer surgery is yet to be agreed on. A high dose above 60Gy may be suitable with no associated patient deaths.

The present study has several limitations associated with its retrospective design. This study could not demonstrate a survival benefit between salvage RT and CCRT compared to the previous reports. In the present study, various chemotherapy regimens were used, but platinum or fluorouracil monotherapies were mainly used. Recent studies have suggested the TP or FP regimens can increase the survival time of recurrent esophageal cancer [12, 21, 29]. There were some selection biases: small sample size, the selection of primary therapy was different among surgeons, as well as the heterogeneity of the combined chemotherapy regimen, recurrent time, RT dose and RT technology.

\section{Conclusion}

Our results suggest that radiotherapy with or without concurrent chemotherapy is an effective and feasible salvage treatment for postoperative lymph node recurrence after occurrence of esophageal squamous cell carcinoma. In view of the shortcomings aforementioned, further research is necessary to identify recurrent esophageal cancer in patients who should be treated with radiotherapy or chemoradiotherapy.

\section{Abbreviations}

3DCRT: Three-dimensional conformal radiation therapy; CCRT: Concurrent chemoradiotherapy; CR: Complete remission; CTV: Clinical target volume; FP: 5-fluorouracil plus platinum; GTV: Gross tumor volume; KPS: Karnofsky Performance Status; OS: Overall survival; PD: Progressive disease; PR: Partial remission; PTV: Planning tumor volume; RT: Radiotherapy alone; SD: Stable disease; TP: Paclitaxel plus platinum; VMAT: Volumetric modulated arc therapy

\section{Acknowledgments}

This work was supported by CSCO-Hengrui Cancer Research Fund (YHR2018-063).

\section{Authors' contributions}

JC contributed to collection and analysis of data and drafting the manuscript; JC and WY performed collection of data; HY and WG provided the critical revision of the manuscript. All authors read and approved the final manuscript.

\section{Funding}

This work was supported by CSCO-Hengrui Cancer Research Fund (YHR2018-063).

\section{Availability of data and materials}

The datasets used and/or analysed during the current study are available from the corresponding author on reasonable request.

Ethics approval and consent to participate Not applicable.
Consent for publication

Not applicable.

\section{Competing interests}

The authors declare that they have no competing interests.

Received: 29 April 2019 Accepted: 10 September 2019

Published online: 18 September 2019

\section{References}

1. Nakagawa S, Kanda T, Kosugi S, Ohashi M, Suzuki T, Hatakeyama K. Recurrence pattern of squamous cell carcinoma of the thoracic esophagus after extended radical esophagectomy with three-field lymphadenectomy. J Am Coll Surg. 2004;198(2):205-11.

2. Dresner SM, Griffin SM. Pattern of recurrence following radical oesophagectomy with two-field lymphadenectomy. Br J Surg. 2000; 87(10):1426-33

3. Mariette C, Balon JM, Piessen G, Fabre S, Van Seuningen I, Triboulet JP. Pattern of recurrence following complete resection of esophageal carcinoma and factors predictive of recurrent disease. Cancer. 2003; 97(7):1616-23.

4. Hsu PK, Wang BY, Huang CS, Wu YC, Hsu WH. Prognostic factors for postrecurrence survival in esophageal squamous cell carcinoma patients with recurrence after resection. J Gastrointest Surg. 2011;15(4):558-65.

5. Kosuga T, Shiozaki A, Fujiwara H, Ichikawa D, Okamoto K, Komatsu S, Otsuji E. Treatment outcome and prognosis of patients with lymph node recurrence of thoracic esophageal squamous cell carcinoma after curative resection. World J Surg. 2011;35(4):798-804.

6. Ma X, Zhao K, Guo W, Yang S, Zhu X, Xiang J, Zhang Y, Li H. Salvage lymphadenectomy versus salvage radiotherapy/chemoradiotherapy for recurrence in cervical lymph node after curative resection of esophageal squamous cell carcinoma. Ann Surg Oncol. 2015;22(2):624-9.

7. Watanabe M, Mine S, Yamada K, Shigaki H, Baba Y, Yoshida N, Kajiyama K, Yamamoto N, Sano T, Baba H. Outcomes of lymphadenectomy for lymph node recurrence after esophagectomy or definitive chemoradiotherapy for squamous cell carcinoma of the esophagus. Gen Thorac Cardiovasc Surg. 2014;62(11):685-92.

8. Motoyama S, Kitamura M, Saito R, Maruyama K, Okuyama M, Ogawa J. Outcome and treatment strategy for mid- and lower-thoracic esophageal cancer recurring locally in the lymph nodes of the neck. World J Surg. 2006;30(2):191-8.

9. Nemoto K, Ariga H, Kakuto Y, Matsushita H, Takeda K, Takahashi C, Takai Y, Yamada S, Hosoi Y. Radiation therapy for loco-regionally recurrent esophageal cancer after surgery. Radiother Oncol. 2001;61(2):165-8.

10. Ma DY, Tan BX, Liu M, Li XF, Zhou YQ, Lu Y. Concurrent three-dimensional conformal radiotherapy and chemotherapy for postoperative recurrence of mediastinal lymph node metastases in patients with esophageal squamous cell carcinoma: a phase 2 single-institution study. Radiat Oncol. 2014;9:28.

11. Fakhrian K, Gamisch N, Schuster T, Thamm R, Molls M, Geinitz H. Salvage radiotherapy in patients with recurrent esophageal carcinoma. Strahlenther Onkol. 2012;188(2):136-42.

12. Kawamoto T, Nihei K, Sasai K, Karasawa K. Clinical outcomes and prognostic factors of chemoradiotherapy for postoperative lymph node recurrence of esophageal cancer. Jpn J Clin Oncol. 2018;48(3):259-64.

13. Zhang WW, Zhu YJ, Yang H, Wang QX, Wang XH, Xiao WW, Li QQ, Liu MZ, $\mathrm{Hu} \mathrm{YH}$. Concurrent radiotherapy and weekly chemotherapy of 5-fluorouracil and platinum agents for postoperative locoregional recurrence of oesophageal squamous cell carcinoma. Sci Rep. 2015;5:8071.

14. Jingu K, Ariga H, Nemoto K, Narazaki K, Umezawa R, Takeda K, Koto M, Sugawara T, Kubozono M, Miyata G, et al. Long-term results of radiochemotherapy for solitary lymph node metastasis after curative resection of esophageal cancer. Int J Radiat Oncol Biol Phys. 2012;83(1):172-7.

15. Takashima S, Takeuchi N, Shiozaki H, Kobayashi K, Morimoto S, Ikezoe J, Tomiyama N, Harada K, Shogen K, Kozuka T. Carcinoma of the esophagus: CT vs MR imaging in determining resectability. AJR Am J Roentgenol. 1991; 156(2):297-302.

16. Palivos T, Yip CK. Optimal population size and endogenous growth. Econ Lett. 1993;41(1):107-10.

17. Carlisle JG, Quint LE, Francis IR, Orringer MB, Smick JF, Gross BH. Recurrent esophageal carcinoma: CT evaluation after esophagectomy. Radiology. 1993;189(1):271-5 
18. Hellwig D, Graeter TP, Ukena D, Groeschel A, Sybrecht GW, Schaefers HJ Kirsch CM. 18F-FDG PET for mediastinal staging of lung cancer: which SUV threshold makes sense? J Nucl Med. 2007:48(11):1761-6.

19. $\mathrm{Ma}$ CL, Li XD, Sun XR, Zhao DB, Yuan YP, Yu YH. Using (18) F-

fluorodeoxyglucose positron emission tomography/computed tomography to estimate the length of gross tumor and involvement of lymph nodes in esophagogastric junction carcinoma. J Cancer Res Ther. 2018;14(4):896-901.

20. Shen H, Li X, Meng L, Ni Y, Wang G, Dong W, Du J. Confirmation of histology of PET positive lymph nodes recovered by hand-video-assisted thoracoscopy surgery. Gene. 2012;509(1):173-7.

21. Bao Y, Liu S, Zhou Q, Cai P, Anfossi S, Li Q, Hu Y, Liu M, Fu J, Rong T, et al. Three-dimensional conformal radiotherapy with concurrent chemotherapy for postoperative recurrence of esophageal squamous cell carcinoma: clinical efficacy and failure pattern. Radiat Oncol. 2013;8:241.

22. Yamashita $H$, Jingu $K$, Niibe $Y$, Katsui $K$, Matsumoto T, Nishina T, Terahara A Definitive salvage radiation therapy and chemoradiation therapy for lymph node oligo-recurrence of esophageal cancer: a Japanese multi-institutional study of 237 patients. Radiat Oncol. 2017;12(1):38.

23. Zhang J, Peng F, Li N, Liu Y, Xu Y, Zhou L, Wang J, Zhu J, Huang M, Gong Y. Salvage concurrent radio-chemotherapy for post-operative local recurrence of squamous-cell esophageal cancer. Radiat Oncol. 2012;7:93.

24. Jingu K, Matsushita H, Takeda K, Umezawa R, Takahashi C, Sugawara T, Kubozono M, Abe K, Tanabe T, Shirata Y, et al. Long-term results of radiotherapy combined with nedaplatin and 5 -fluorouracil for postoperative loco-regional recurrent esophageal cancer: update on a phase II study. BMC Cancer. 2012;12:542.

25. Yang H, Feng C, Cai BN, Yang J, Liu HX, Ma L. Comparison of threedimensional conformal radiation therapy, intensity-modulated radiation therapy, and volumetric-modulated arc therapy in the treatment of cervical esophageal carcinoma. Dis Esophagus. 2017;30(2):1-8.

26. Haefner MF, Lang K, Verma V, Koerber SA, Uhlmann L, Debus J, Sterzing F. Intensity-modulated versus 3-dimensional conformal radiotherapy in the definitive treatment of esophageal cancer: comparison of outcomes and acute toxicity. Radiat Oncol. 2017;12(1):131.

27. Baxi SH, Burmeister B, Harvey JA, Smithers M, Thomas J. Salvage definitive chemo-radiotherapy for locally recurrent oesophageal carcinoma after primary surgery: retrospective review. J Med Imaging Radiat Oncol. 2008:52(6):583-7.

28. Jeene PM, Versteijne E, van Berge Henegouwen Ml, Bergmann JJ, Geijsen ED, Muller K, van Laarhoven HW, Hulshof MC. Definitive chemoradiation for locoregional recurrences of esophageal cancer after primary curative treatment. Dis Esophagus. 2017;30(2):1-5.

29. Jingu K, Nemoto K, Matsushita H, Takahashi C, Ogawa Y, Sugawara T, Nakata E, Takai Y, Yamada S. Results of radiation therapy combined with nedaplatin (cis-diammine-glycoplatinum) and 5-fluorouracil for postoperative locoregional recurrent esophageal cancer. BMC Cancer. 2006;6:50

30. Shioyama Y, Nakamura K, Ohga S, Nomoto S, Sasaki T, Yamaguchi T, Toba T, Yoshitake T, Terashima H, Honda H. Radiation therapy for recurrent esophageal cancer after surgery: clinical results and prognostic factors. Jpn J Clin Oncol. 2007:37(12):918-23.

31. Raoul JL, Le Prise E, Meunier B, Julienne V, Etienne PL, Gosselin M, Launois B. Combined radiochemotherapy for postoperative recurrence of oesophageal cancer. Gut. 1995;37(2):174-6.

\section{Publisher's Note}

Springer Nature remains neutral with regard to jurisdictional claims in published maps and institutional affiliations.

Ready to submit your research? Choose BMC and benefit from:
- fast, convenient online submission
- thorough peer review by experienced researchers in your field
- rapid publication on acceptance
- support for research data, including large and complex data types
- gold Open Access which fosters wider collaboration and increased citations
- maximum visibility for your research: over 100M website views per year
At BMC, research is always in progress.
Learn more biomedcentral.com/submissions

